AperTO - Archivio Istituzionale Open Access dell'Università di Torino

\title{
Suzuki cross-couplings of (hetero)aryl chlorides in the solid-state
}

\section{This is the author's manuscript}

Original Citation:

Availability:

This version is available http://hdl.handle.net/2318/119265

since 2017-10-02T15:46:34Z

Published version:

DOI:10.1039/c2nj40064b

Terms of use:

Open Access

Anyone can freely access the full text of works made available as "Open Access". Works made available under a Creative Commons license can be used according to the terms and conditions of said license. Use of all other works requires consent of the right holder (author or publisher) if not exempted from copyright protection by the applicable law. 


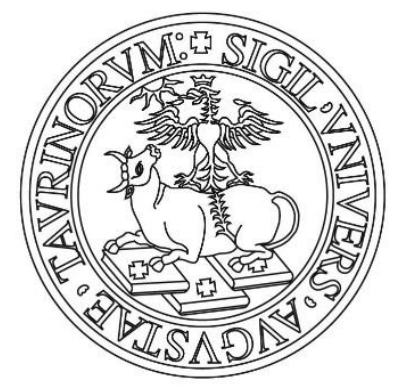

\section{UNIVERSITÀ DEGLI STUDI DI TORINO}

This is an author version of the contribution published on:

Questa è la versione dell'autore dell'opera:

[New Journal of chemistry, Vol. 36, 2012, DOI:10.10397c2nj40064b]

ovvero [Giancarlo Cravotto, Davide Garella, Silvia Tagliapietra, Achim Stolle, Stefan

Schüßler, Silke E.S. Leonhardt, Bernd Ondruschka, Vol.36, RCS Ed., 2012, pagg.1304-

The definitive version is available at:

La versione definitiva è disponibile alla URL:

[http://pubs.rsc.org/en/journals/journalissues/nj] 


\section{Suzuki Cross-Couplings of (Hetero)Aryl Chlorides in the solid-state}

\section{Giancarlo Cravotto $^{\mathrm{a}, *}$, Davide Garella ${ }^{\mathrm{a}}$, Silvia Tagliapietra ${ }^{\mathrm{a}}$, Achim Stolle ${ }^{\mathrm{b}}$, Stefan Schüßler ${ }^{b}$, Silke E.S. Leonhardt ${ }^{b}$, Bernd Ondruschka ${ }^{b}$}

${ }_{5}$ Received (in $\left.X X X, X X X\right) X$ th $X X X X X X X X X 20 X X$, Accepted Xth $X X X X X X X X X 20 X X$ DOI: 10.1039/b000000x

The ultrasound-assisted cross-linking of chitosan with hexamethylene diisocyanate with the simultaneous incorporation of $\mathrm{Pd}(\mathrm{OAc})_{2}$ resulted in a catalyst which is suitable for the solid-state Suzuki cross-coupling of poorly reactive (hetero)aryl chlorides with phenylboronic acid. Reactions were carried out solvent-free in ${ }_{10}$ planetary ball mill allowing the catalyst to be recycled several times.

\section{Introduction}

Reactions in ball mills have attracted serious attention in organic synthesis circles during the last decade. ${ }^{1,2}$ This method allows reactions in the solid state to be carried out and possibly reduces solvent amount ${ }^{3-6}$ which makes it attractive for other application fields as well. ${ }^{7}$ Pd-catalyzed cross-couplings ${ }_{15}$ from the Suzuki-,${ }^{8-10}$ Heck-,${ }^{11}$ or Sonogashira-type reactions, ${ }^{12,13}$ as well as $\mathrm{Cu}$-catalyzed click reactions $(\mathrm{CuAAC}),{ }^{14}$ and the homo-coupling of terminal alkynes, ${ }^{15}$ make use of metal salts or metal complexes which are difficult to separate from the solid reaction mixtures afterwards.

Additionally, the application of aryl chlorides instead of bromides or iodides as cross-coupling partners has only so far afforded zero or minor yields. An example of this is a Suzuki reaction in the presence of ${ }_{20} \mathrm{KF}-\mathrm{Al}_{2} \mathrm{O}_{3}$ using a planetary ball mill. ${ }^{10}$ This inorganic solid material was used for the in situ generation of the base needed for the reaction and $\mathrm{Pd}(\mathrm{OAc})_{2}$ was used as the catalyst. ${ }^{10,16}$ The synthetic procedure was very efficient with aryl iodides and bromides but failed when it came to the poorly reactive aryl chlorides. ${ }^{10}$ Similar observations were reported when the more reactive reagent system $\operatorname{Pd}\left(\mathrm{PPh}_{3}\right)_{4}$ and $\mathrm{K}_{2} \mathrm{CO}_{3}$ (catalyst and base, respectively) was used. ${ }^{8}$ All the results reported in the literature gave no ${ }_{25}$ reaction or very low yields with these substrates. ${ }^{8-10,16}$

With the aim of finding conditions which may widen the application of this method, we realized that the physicochemical properties of the catalyst could play a fundamental role in the solid state. Our candidate for Pd-catalyzed reactions is a cross-linked chitosan/Pd(II) catalyst that has already been tested as a heterogeneous catalyst in microwave-assisted reactions. ${ }^{17}$ Although chitosan (CS) modification requires 
some tricky procedures, ${ }^{18}$ this material is cheap, stable and biodegradable, making it suitable for Pdcatalyzed Suzuki reactions. ${ }^{19-21}$ Despite the fact that several metal-catalyzed reaction protocols for ball milling synthesis have been developed, only in one case the possibility of catalyst recycling was included. ${ }^{22}$ These authors described the synthesis of oximes with $\mathrm{Bi}_{2} \mathrm{O}_{3}$ as a catalyst by grounding in a ${ }_{5}$ mortar the reacting mixture with a pestle.

\section{Experimental}

\section{Materials}

Commercially available reagents and solvents were used without further purification. Medium molecular weight CS was purchased from Sigma Aldrich.

\section{${ }_{10}$ Catalyst preparation}

$\mathrm{CS}(5.0 \mathrm{~g})$ was dissolved in $0.1 \mathrm{~N} \mathrm{HCl}(350 \mathrm{~mL})$ in a 11 round-bottom cylindrical flask at $60^{\circ} \mathrm{C}$ under sonication with a titanium horn $(19.8 \mathrm{kHz}, 70 \mathrm{~W})$ for less than $1 \mathrm{~h}$. A solution of $\mathrm{Pd}(\mathrm{OAc})_{2}(2.23 \mathrm{mmol}$, $500 \mathrm{mg})$ in $0.1 \mathrm{~N} \mathrm{HCl}(50 \mathrm{~mL})$ was added after $5 \mathrm{~min}$ at $50^{\circ} \mathrm{C}$ while the sonication was run at reduced power $(50 \mathrm{~W})$. Hexamethylene diisocyanate (HMDI; $37.0 \mathrm{mmol}, 6 \mathrm{~mL}$ ) was added dropwise at the same ${ }_{15}$ temperature of $50^{\circ} \mathrm{C}$ and was sonicated for $10 \mathrm{~min}$ at $60 \mathrm{~W}$ at which point complete gelation occurred. The gel was heated for $2 \mathrm{~h}$ at $50^{\circ} \mathrm{C}$ and a yellowish solid material formed which was then transferred to a mortar and triturated with a $0.5 \mathrm{~N} \mathrm{NaOH}$ solution until $\mathrm{pH} 5$ was reached. The solid residue was filtered, washed with water, acetone and diethylether (each solvent $150 \mathrm{~mL}$ ), and dried overnight under vacuum. This procedure afforded $8.23 \mathrm{~g}$ of the $\mathrm{Pd}(\mathrm{II})$-loaded urethane/urea-bridged CS derivative $\triangleq$ catalyst ${ }_{20} \mathrm{HMDI}-\mathrm{CS} / \mathrm{Pd}$.

\section{Catalyst characterization}

FT-IR spectra were recorded on a Perkin-Elmer model 2000 spectrometer in the $400-4000 \mathrm{~cm}^{-1}$ range at a resolution of $0.2 \mathrm{~cm}^{-1}$ using the ATR-method. TG-curves were recorded on the TA Instrument TGA 2050 (Shimadzu). The analyses were carried out with a constant heating rate of $10 \mathrm{~K} \mathrm{~min}^{-1}$ from 50 to ${ }_{25} 700^{\circ} \mathrm{C}$ under atmospheric conditions. The metal content of the catalysts was determined by ICP-MS on a Quadrupole-ICP-MS X Series II (Thermo Fisher Scientific) after the solid catalyst samples were digested in $\mathrm{HNO}_{3}$ and aqua regia. The oxidation state of the adsorbed palladium was determined by measuring the binding energy $(\mathrm{Eb})$ of the Pd 3d-core level by X-ray photoelectron spectroscopy (XPS) with a Quantum 2000 (PHI Co., Chanhassen, MN, USA) using a focused monochromatic Al Ka-source ${ }_{30}(1486.7 \mathrm{eV})$. Spectra were normalized to the $\mathrm{C} 1 \mathrm{~s}$ peak. 


\section{Catalytic testing}

Ball milling was conducted using a planetary ball mill (PM100; Retsch $\mathrm{GmbH}$ ) equipped with a single milling beaker (stainless steel, $125 \mathrm{~mL}$ ). For the experiments $15 \times 10 \mathrm{~mm}$ milling balls of the same material were applied. The prepared catalyst $(1 \mathrm{~g})$, aryl halide $(0.25 \mathrm{mmol})$, phenyl-boronic acid $(0.27$ s $\mathrm{mmol}, 33 \mathrm{mg})$, and $\mathrm{K}_{2} \mathrm{CO}_{3}(0.5 \mathrm{mmol}, 69 \mathrm{mg})$ were added to the milling balls one after the other. The reaction mixture was subsequently milled at $600 \mathrm{~min}^{-1}$ for either 90 or $120 \mathrm{~min}$. Every $30 \mathrm{~min}$ the direction of rotation was inverted. The reaction products were dissolved in EtOAc $(3 \times 15 \mathrm{~mL})$. The supported catalyst, insoluble in the organic solvent, was separated by filtration and was washed with acetone $(3 \times 15 \mathrm{~mL})$, dried under vacuum and reused in a new reaction. The products were analyzed by ${ }_{10}$ GC-MS. The yields determined by GC-MS were comparable with the yields of the isolated products. Purification was performed via flash-chromatography on a silica column (CombyFlash $\mathrm{Rf}^{\circledR}$ Teledyne ISCO) using hexane/ethyl acetate mixtures as eluents. Conversions and yields were initially determined by GC-MS and confirmed by chromatographic separation $(+2 \%)$.

\section{Product analysis}

${ }_{15}$ GC-MS measurements were performed on an Agilent Technologies 6850 Network GC System with a 5973 Network Mass Selective Detector using a capillary column (length $30 \mathrm{~m}$, i. d. $0.25 \mathrm{~mm}$, film thickness $0.25 \mu \mathrm{m})$. GC conditions were as follows; injection split 1:20, injector temperature $250^{\circ} \mathrm{C}$, detector temperature $280^{\circ} \mathrm{C}$. The temperature program ran from $50^{\circ} \mathrm{C}(3 \mathrm{~min})$ to $80^{\circ} \mathrm{C}$ at $3^{\circ} \mathrm{C} / \mathrm{min}$ and $80^{\circ} \mathrm{C}$ to $300^{\circ} \mathrm{C}$ at $10^{\circ} \mathrm{C} / \mathrm{min}(30 \mathrm{~min})$. Helium was used at $25 \mathrm{kPa}$ as the carrier gas.

\section{${ }_{20}$ Results and Discussion}

The ultrasound-assisted synthesis of the CS catalyst HMDI-CS/Pd resulted in a solid material which was characterized using FT-IR, XPS-spectroscopy, and thermal analysis (TGA, DTA). The metal content of the catalysts, prior to and after their application in Suzuki cross-couplings (Scheme 1), was determined with ICP-MS analysis. The addition of HMDI to the CS solution containing $\mathrm{Pd}(\mathrm{OAc})_{2}$ resulted in the ${ }_{25}$ cross-linking of the polymer chains, a regular distribution of the metal and a considerable catalytic activity. ${ }^{17}$

\section{Structural properties of the catalyst}

To compare the properties of CS and the catalyst, FTIR and thermal analysis of both materials have been carried out. Figure 1 shows the overlay of the infrared spectra for pure CS and HMDI-CS/Pd. Pure CS ${ }_{30}$ shows a broad band at around $3320 \mathrm{~cm}^{-1}$ which is caused by $\mathrm{OH}-, \mathrm{NH}_{2}$ - as well as $\mathrm{CONH}$-vibrations 
(amide $=$ non-deacetylated glucosamine groups). ${ }^{19}$ After cross-linking with HMDI and in situ deposition of $\mathrm{Pd}$, the band appears less broad. This indicates that the diisocyanate reacted with the hydroxyl and amino groups of the polymer. The resulting urea- and urethane-linkages also contain the CONHfunction, which are responsible for this band. It should be mentioned that isocyanate-groups do not ${ }_{5}$ necessarily react with the polymer, they can also be hydrolyzed by the solvent which would result in new amine-functions. Another indicator for successful cross-linking is the band at $2930 \mathrm{~cm}^{-1}$ which refers to $\mathrm{CH}_{2}$-vibrations. After polymer cross-linking, there is a higher number of $\mathrm{CH}_{2}$-groups in the polymer, resulting in a stronger and sharper absorption band in the IR-spectrum. New bands appear at approximately 1600 and $1260 \mathrm{~cm}^{-1}$ which are assigned to the urea- and urethane-functions $(\mathrm{C}=\mathrm{O}-$ and ${ }_{10} \mathrm{C}-\mathrm{N}$-vibrations) in the polymer. The absorption at $1026 \mathrm{~cm}^{-1}$ indicates $\mathrm{C}-\mathrm{O}-\mathrm{C}$ vibrations which are typical for carbohydrates. This band slightly decreases in intensity. This could be caused by the chaincleavage that may occur in the acidic solvent that was used during the cross-linking under power ultrasound.

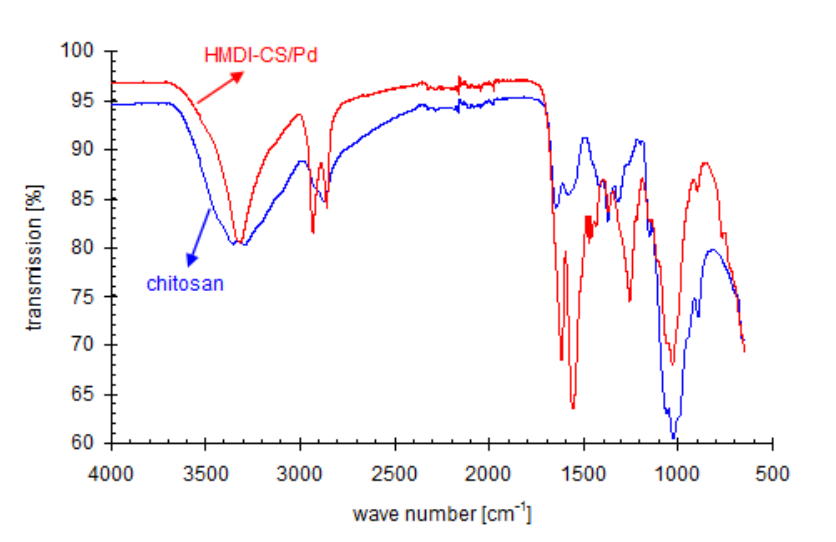

Fig. 1 FTIR-spectra of pure CS and cross-linked catalyst HMDI-CS/Pd.

Further evidence of successful cross-linking with HMDI can be found in the TGA-analysis (Figure 2). At the beginning of the measurement, a mass loss of approximately $10 \%$ was observed. This is assigned to absorbed water. It is important to note that the two curves show different slopes. Pure CS loses the ${ }_{20}$ absorbed water faster than the cross-linked polymer. In fact, the modified polymer has a network-like structure which is responsible for the slower release of water. Moreover, the cross-linking caused an increased amount of polar groups in the polymer, which can absorb more water and bind it via hydrogen bonds. The TGA-curve shows that the cross-linked polymer indeed exhibits a greater (but slower) weight loss. 


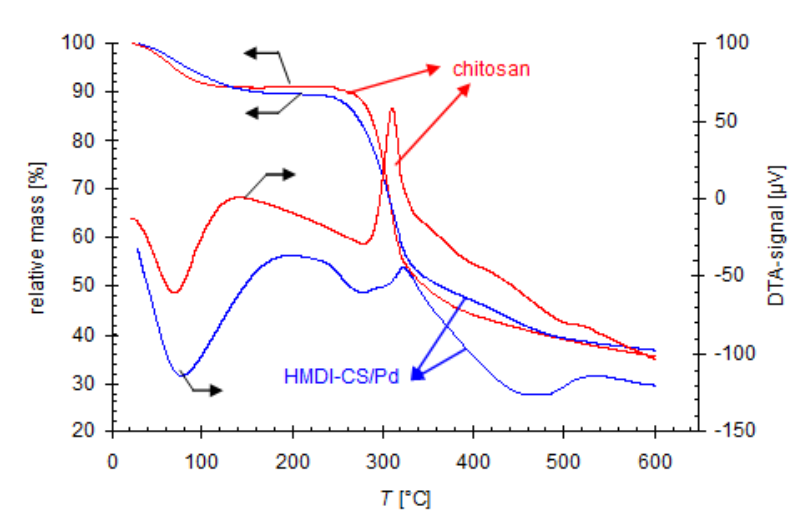

Fig. 2 TGA- and DTA-curves for pure CS and HMDI cross-linked catalyst HMDI CS/Pd.

The metal loading of the catalysts was checked by ICP-analyses. Due to impurities, non-modified CS ${ }_{5}$ exhibited a Pd-loading of $<9.4 * 10^{-4} \mathrm{wt} \%$, which is a number of magnitudes lower than found in the prepared catalyst.

Analysis of the Pd-loaded polymer directly after catalyst preparation and after the forth reaction cycle (cf. Table 1) resulted in Pd-contents of $2.3 \pm 0.3$ and $2.1 \pm 0.3 \mathrm{wt} \%$, respectively. Thus, the catalyst system proves its stability with respect to metal leaching. However, catalyst recycling entailed an ${ }_{10}$ average weight loss of $3.4 \%$ relative to the initial catalyst mass. XPS-analysis of the oxidation state resulted in a similar $E_{\mathrm{b}}$, for the $\mathrm{Pd} 3 \mathrm{~d}_{5 / 2}$ core level, to the value reported in literature. ${ }^{17}$

\section{Catalytic testing}

Catalytic tests were carried out by comminuting phenylboronic acid (1) and several aryl halides (2a-i) together with the catalyst and $\mathrm{K}_{2} \mathrm{CO}_{3}{ }^{8}$ which was used as the base in a stainless steel milling beaker ${ }_{15}$ mounted on a planetary ball mill. The reaction with unloaded CS samples led to no conversion at all. ${ }^{17,19}$ Solid-state reactions in presence of HMDI cross-linked CS/Pd(II) afforded the cross-coupled products (3a-i) and biphenyls which originated from homo-coupling of the aryl halide (4a-d, Ullmann reaction; Scheme 1). ${ }^{23}$ The amount of biphenyl (3e) from the homo-coupling of $\mathbf{1}$ was very low $(<1 \%)$ for most of the reactions. The amount of homo-coupled products $\mathbf{4 a - d}$ is considerably higher for the present CS${ }_{20}$ based catalyst system (Table 1) than for other Suzuki cross-coupling procedures in ball mills using $\mathrm{Pd}(\mathrm{OAc})_{2}{ }^{9,10}$ or $\mathrm{Pd}\left(\mathrm{PPh}_{3}\right)_{4} .{ }^{8}$ As expected, the reactions of aryl iodides (2a,b) and aryl bromides $(\mathbf{2} \mathbf{c}, \mathbf{d})$ lead to higher reaction rates, resulting in quantitative conversion after $90 \mathrm{~min}$, whereas the chlorides afforded longer reaction times (120 $\mathrm{min})$. The increased formation of homo-coupling products 4 , was evident in recycling experiments. Thus, with $p$-iodoanisole (2a), the yield of $\mathbf{4 a}$ was $35 \%$ in the second ${ }_{25}$ run, compared to $25 \%$ after the first. $m$-iodophenol $(\mathbf{2 b})$, however, exclusively gave the cross-coupling 
product 3b. Similarly to $\mathbf{2 a}, p$-bromoacetophenone (2c) and $p$-bromoanisole (2d) gave $84 \%$ and $72 \%$ yields of cross-coupling adducts ( $\mathbf{3} \mathbf{c}$ and $\mathbf{3 d}$ respectively) and 15\%, 22\% of homo-coupling products (4c, $\mathbf{4 d}$ respectively) (Table 1). In a trial with $\mathbf{2 c}$, no reaction occurred in the absence of 1 and only a $5 \%$ yield of $\mathbf{4} \mathbf{c}$ was isolated. The higher reactivity and selectivity of aryl bromides towards Suzuki cross-coupling, ${ }_{5}$ when compared to iodides, has also been reported by other authors. ${ }^{8-10}$ The formation of the dehalogenated aromatics was observed among the side reactions.

Beside the reactions with aryl iodides and bromides, noteworthy results were also obtained with the less reactive aryl chlorides 2e-i (Tab. 1). To the best of our knowledge this is the first report in which aryl chlorides have been cross-coupled with $\mathbf{1}$ in a ball mill affording $>10 \%$ yield.

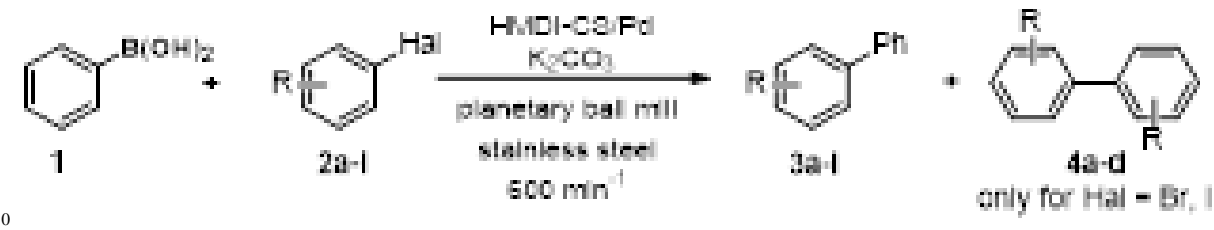

Scheme 1. Suzuki cross-coupling reaction of aryl halides in a planetary ball mill (cf. Tab. 1).

Reports by Schneider and Ondruschka ${ }^{10}$ and Klingensmith and Leadbeater ${ }^{9}$ reported yields of only $6 \%$ and $2 \%$ for the cross-coupling of chlorobenzene (2e) and $p$-chlorotoluene with 1, respectively. Moreover, is we exclusively recovered cross-coupling (3e-i) products in these new experiments (Table 1). 
Table 1. Suzuki reaction of aryl halides (2a-i; Scheme 1) with phenylboronic acid (1) in a ball mill using HMDI-CS/Pd as catalyst. ${ }^{\mathrm{a}}$

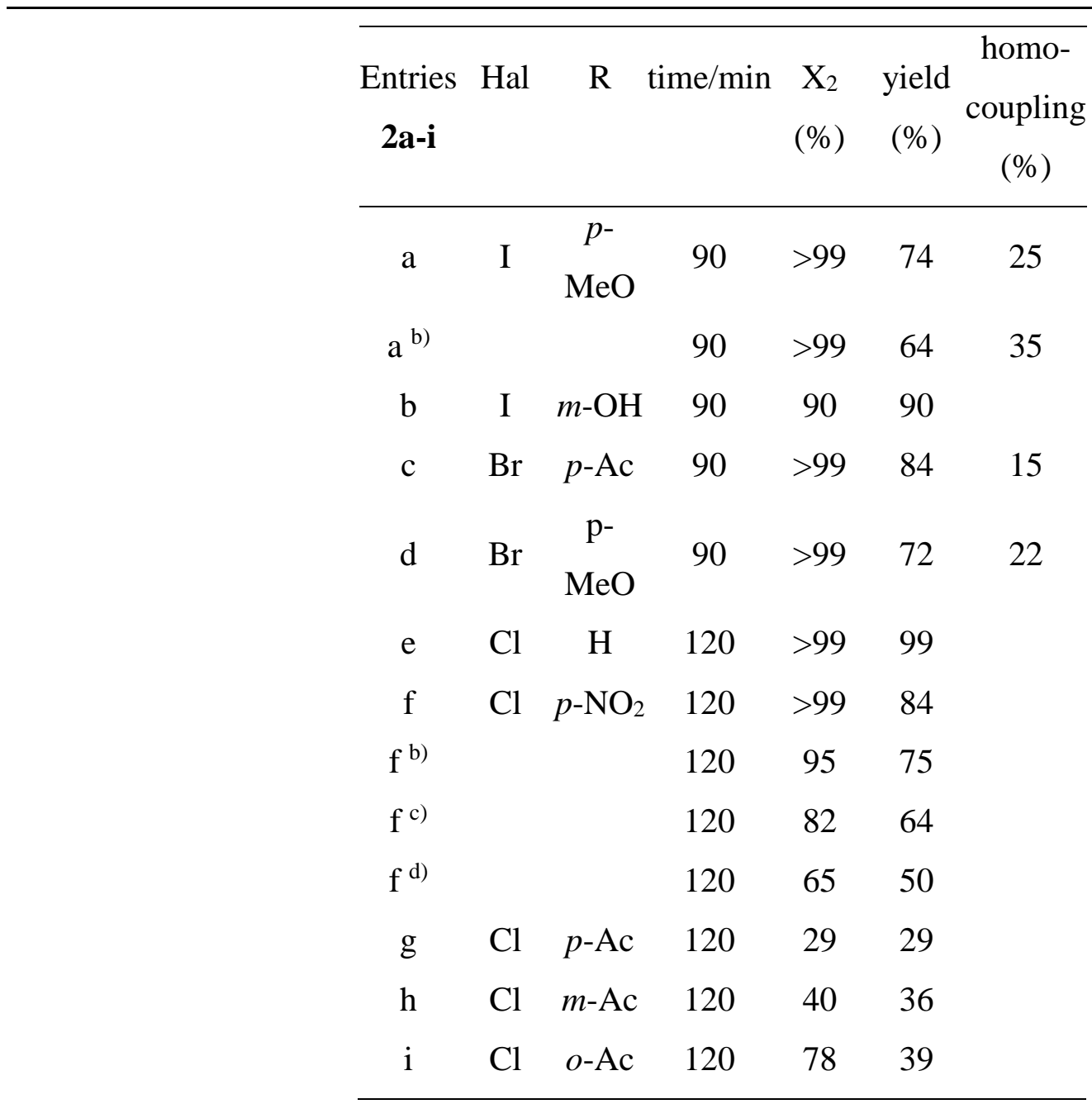

$\mathrm{X}_{2}=$ conversion of 2 .

a) Reaction conditions: $1 \mathrm{~g}$ catalyst, $0.27 \mathrm{mmol} \mathrm{1,0.25} \mathrm{mmol} \mathrm{2,} 0.5 \mathrm{mmol} \mathrm{K} \mathrm{CO}_{3}$; planetary ball mill, milling beaker (stainless steel, 125 $5 \mathrm{~mL}$ ), milling balls (stainless steel, 15x10 mm); $600 \mathrm{~min}^{-1}$. Distribution from GC-MS analysis as mean of three runs.

Catalyst application: b) $2^{\text {nd }}$ run. c) $3^{\text {rd }}$ run. d) $4^{\text {th }}$ run.

Obviously, the stronger $\mathrm{C}-\mathrm{Cl}$ bond in 2e-i favours oxidative addition to the catalyst over the dehalogenation accompanied by homo-coupling seen in 2a-d. High conversions and high yields were ${ }_{10}$ obtained with $2 \mathbf{e}$ and $p$-chloronitrobenzene (2f). With $p$-chloroacetophenone (2g), the reaction proceeded slowly with partial conversion but with high chemoselectivity, while higher conversions and yields were detected with the $m$ - (2h) and $o$-isomer (2i). We suppose that these slight differences could arise from the coordinating effect of the carbonyl group on the palladium, stronger in the ortho and meta positions, thus favouring the oxidative addition. In the reaction with $\mathbf{2 f}$, the catalyst was recycled three times with is a loss in activity. ICP-analyses of the catalyst after its application revealed that leaching is not so 
significant as to explain the activity loss. Weight loss during catalyst recycling is probably responsible for the observed effect. Using heterocyclic 2-chloropyridine (5a) and 4-benzoxazole (5b) in the reaction with 1 afforded the cross-coupling products $6 \mathbf{a}$ and $\mathbf{6 b}$ in 79 and 62\% yields, respectively (Scheme 2). Competitive aryl-aryl coupling can be slightly reduced when working under argon atmosphere, this, ${ }_{5}$ however, is a task that cannot easily be when using a planetary ball mill. In comparison to results previously published for the cross-coupling of bromo- $N$-heteroarenes in a similar ball mill, ${ }^{8}$ the yields obtained with the present catalyst are considerably higher, although the reaction times are longer.

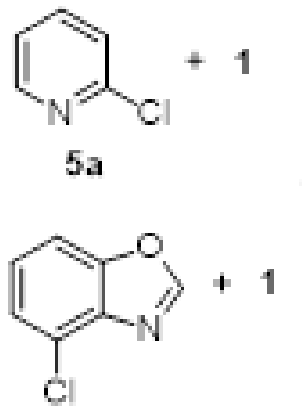

$5 \mathrm{~b}$
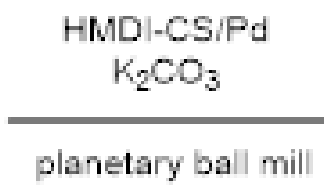

stainless steel $120 \mathrm{~min}^{6} 60 \mathrm{~min}^{-1}$
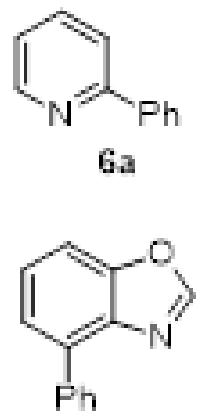

$6 \mathrm{~b}$

\section{$79 \%$ yield}

$\left(X_{5 a}=99 \%\right)$

$62 \%$ yield

$\left(X_{5 t}=90 \%\right)$

Scheme 2. Solid state Suzuki cross-coupling of heteroaryl chlorides (5) with phenylboronic acid (1) in a planetary ball mill (conditions see Table 1; $\mathrm{X}=$ conversion).

\section{Conclusions}

In summary, we have reported an interesting protocol for Suzuki cross-couplings under ball milling conditions using a HMDI cross-linked CS/Pd-derivative as catalyst. The catalyst was prepared in water via sonochemical cross-linking with HMDI in the presence of the metal salt. This catalyst can be reused ${ }_{15}$ three times and shows low metal leaching during its application in Suzuki cross-coupling of aryl chlorides. The average to high yields that were obtained with several aryl chlorides, compared with the poor results reported in literature, may open the door to reactions with poorly reactive substrates in the ball mill and possibility to catalyst recycling.

\section{Acknowledgement}

${ }_{20}$ Financial support from MIUR (PRIN 2008 "A Green Approach to Process Intensification in Organic Synthesis") is gratefully acknowledged.

\section{Notes and references}

${ }^{a}$ Dipartimento di Scienza e Tecnologia del Farmaco, University of Torino, Via P. Giuria 9, 10125 Torino, Italy. Fax: +39011 6707687; Tel:+39 011 6707684; E-mail: giancarlo.cravotto@unito.it 
${ }^{b}$ Institute for Technical Chemistry and Environmental Chemistry (ITUC), Friedrich-Schiller University Jena, Lessingstr. 12, 07743 Jena, Germany

1 B. Rodríguez, A. Bruckmann, T. Rantanen, C. Bolm, Adv. Synth. Catal., 2007, 349, 2213.

2 A. Stolle, T. Szuppa, S. E. S. Leonhardt, B. Ondruschka, Chem. Soc. Rev., 2011, 40, 2317.

3 K. Tanaka, F. Toda, Chem. Rev., 2000, 100, 1025.

4 K. Tanaka, Solvent-free Organic Synthesis (2nd Ed.), Wiley-VCH, Weinheim, 2008.

5 G. Kaupp, J. Phys. Org. Chem., 2008, 21, 630.

6 M. O’Brien, R. Denton, S. V. Ley, Synthesis, 2011, 1157.

${ }_{10} 7$ S. L. James, C. J. Adams, C. Bolm, D. Braga, P. Collier, T. Friščić, F. Grepioni, K. D. M. Harris, G. Hyett, W. Jones, A. Krebs, J. Mack, L. Maini, A. G. Orpen, I. P. Parkin, W. C. Shearouse, J. W. Steed, D. C. Waddell, Chem. Soc. Rev. 2012, DOI: 10.1039/c1cs15171a.

8 S. Feldbæk Nielsen, D. Peters, O. Axelsson, Synth. Commun., 2000, 30, 3501.

9 L. M. Klingensmith, N. E. Leadbeater, Tetrahedron Lett., 2003, 44, 765.

is 10 F. Schneider, B. Ondruschka, ChemSusChem., 2008, 1, 622.

11 E. Tullberg, D. Peters, T. Frejd, J. Organomet. Chem., 2004, 689, 3778.

12 D. A. Fulmer, W. C. Shearhouse, S. T. Mendonza, J. Mack, Green Chem., 2009, 11, 1821.

13 R. Thorwirth, A. Stolle, B. Ondruschka, Green Chem., 2010, 12, 985.

14 R. Thorwirth, A. Stolle, B. Ondruschka, A. Wild, U. S. Schubert, Chem. Commun., 2011, 47, 4370.

2015 R. Schmidt, R. Thorwirth, T. Szuppa, A. Stolle, B. Ondruschka, H. Hopf, Chem.-Eur. J., 2011, 17, 8129.

16 F. Bernhardt, R. Trotzki, T. Szuppa, A. Stolle, B. Ondruschka, B., Beilstein J. Org. Chem., 2010, 6, No. 7.

17 K. Martina, S. E. S. Leonhardt, B. Ondruschka, M. Curini, A. Binello, G. Cravotto, J. Mol. Catal. A: ${ }_{25}$ Chem., 2011, 334, 60.

18 G. Cravotto, S. Tagliapietra, M. Trotta, B. Robaldo, Ultrason. Sonochem., 2005, 12, 95.

19 S. E. S. Leonhardt, A. Stolle, B. Ondruschka, G. Cravotto, C. De Leo, K. D. Jandt, T. F. Keller, App. Catal., A, 2010, 379, 30.

20 H. -F. Zhang, L. Zhang, Y, -C. Cui, React. Funct. Polym., 2007, 67, 322.

${ }_{30} 21$ X. Xu, P. Liu, S. Li, P. Zhang, X. Wang, React. Kinet. Catal. Lett., 2006, 88, 217.

22 L. Saikia, J.M. Baruah, A.J. Thakur Org. Med. Chem. Lett. 2011, 1, 12.

23 G. Cravotto, M. Beggiato, A. Penoni, G. Palmisano, S. Tollari, J. -M. Lévêque, W. Bonrath, Tetrahedron Lett., 2005, 46, 2267. 
